\title{
A Comprehensive Research Roadmap for ICT and Ageing
}

\author{
Luis M. CAMARINHA-MATOS ${ }^{1}$, Hamideh AFSARMANESH ${ }^{2}$, \\ Filipa FERRADA ${ }^{1}$, Ana Inês OLIVEIRA ${ }^{\mathbf{1}}$, João ROSAS ${ }^{1}$ \\ ${ }^{1}$ Universidade Nova de Lisboa, Uninova Institute, Campus de Caparica, \\ 2829-516 Monte Caparica, Portugal, \\ cam@uninova.pt \\ ${ }^{2}$ Informatics Institute, University of Amsterdam, \\ Postbus 94323, 1090 GH Amsterdam, The Netherlands, \\ h.afsarmanesh@uva.nl
}

\begin{abstract}
Ageing societies face tough challenges namely in terms of the pressure on their healthcare and social security systems, which makes it urgent to find new models to accommodate current demographic trends. A possible answer to this challenge may come from new integrated and technology-supported services. In this direction, a European roadmapping initiative has addressed the implementation of a new vision for technological support to ageing. The main findings of this initiative are presented as a roadmap, which synthesizes the contribution of a large number of stakeholders coming from different backgrounds.
\end{abstract}

Keywords: Roadmap, ICT and Ageing, Collaborative care ecosystems.

\section{Introduction}

Industrialized countries need to cope with the challenges of a growing demographic unbalance which is due to the rapidly increasing proportion of the elderly. This situation raises important sustainability issues for the society, namely due to the pressure put on its healthcare system and social care in general. Furthermore, migratory patterns within Europe have resulted in movement from rural to urban areas and to more affluent member states. This movement has resulted in reduction of traditional extended family structures and community cohesion, and has led to a growth in the perception of isolation and loneliness, especially amongst older people. Realizing the critical issues of our ageing society, the European Commission has made a considerable investment in e-inclusion, Information and Communication Technologies (ICT) and ageing in its Framework Programmes. A number of related initiatives and experimental approaches have also emerged in other geographical regions, e.g., Australia, Canada, Japan and the United States. As a result, good progress has been made in various aspects of einclusion and particularly with regard to assistive technologies with the identification of a set of good practices and existing gaps.

Although a substantial and continued effort has been observed in the last decade on ICT and Ageing, most projects have been focused on provision of assistance to senior citizens in that phase of life when a reduction of physical and even mental capabilities is observed [1], [2], [3], [4]. Current studies, however, recognize the importance of considering a broader perspective in the ageing process. In fact, more recently there is a growing recognition that the adoption of the concept of "active ageing" [5], [6], [7], [8] instead of a restricted perspective of healthcare for elderly, provides a more appropriate understanding of the needs of later phases of life. If ICT is to achieve its full potential in enhancing the capabilities of citizens to age actively and with dignity, further research and technological development need to build on these results and be guided by a strategic roadmap which provides an extended look at the future of active ageing and ageing well as a result of the knowledge and imagination of stakeholders, including experts, visionaries and drivers of change in this field.

In this context, the BRAID project [9] was launched with the aim of developing a comprehensive RTD roadmap for active ageing by consolidating and extending existing roadmaps in close interaction with relevant stakeholders. The proposed strategic research agenda, when successfully implemented, shall take the society from the current situation, i.e. the baseline, to a desirable future, i.e. a vision of what society wishes to reach in the future. Although we started with previous partial roadmaps (e.g. AALIANCE [10], CAPSIL [11], ePAL [12], SENIOR [13]) and other recommendations that have originated in 
contemporary research initiatives, we further pursued a holistic understanding of the ageing process and its needs in all its phases, trying to maximize the benefits for senior citizens and society.

While focused on ICT, the roadmap needs to take into account the socio-organizational context, which is crucial for the acceptance of new technological solutions. Therefore, in addition to ICT-related research actions, the proposed roadmap is complemented with a number of policy recommendations or socioeconomic research actions.

The remaining of this paper starts with an introduction of the methodological approach for roadmapping followed by a brief introduction to BRAID's vision and gap analysis. Section 4 presents the proposed plan of actions organized according to major life settings. Roadmap validation approach and results are discussed in Section 5. The contribution of the collaborative networks discipline for the provision of integrated care services is discussed in Section 6 . Implementation aspects and conclusions complement the paper.

\section{Methodological Approach}

Our understanding of roadmap includes three main components, as illustrated in Figure 1.
Within the roadmap, the "vision" defines the ultimate goals to be achieved through applying a number of "planned actions" (which is often itself called the "roadmap") to the "baseline" (which is the current state of society). A wellconceived roadmap needs to be drawn on the basis of an inspiring vision of what society desires to achieve in the future [14]. Therefore, we proceed with a vision-driven roadmapping approach in order to derive a plan of actions that, if successfully implemented, will help us achieve the established vision.

As it is naturally difficult to forecast the future, and even to understand all inter-dependencies among the driving forces of the society, a meaningful roadmap needs to be the result of contributions from relevant visionaries and stakeholders in the field. In order to properly integrate and put the various contributions in the right context, it is important to follow a systematic process. Most literature on roadmapping is focused on presenting specific roadmaps, giving little hints on the followed method. In fact, one of the most prevalent approaches in Europe seems to mainly rely on the organization of discussion workshops with a considerable number of stakeholders, expecting, in this way, to extract relevant conclusions. Our roadmapping method, which includes a number of systematic steps (Figure 2), is adapted from the "standard" scientific method and has proven to be effective

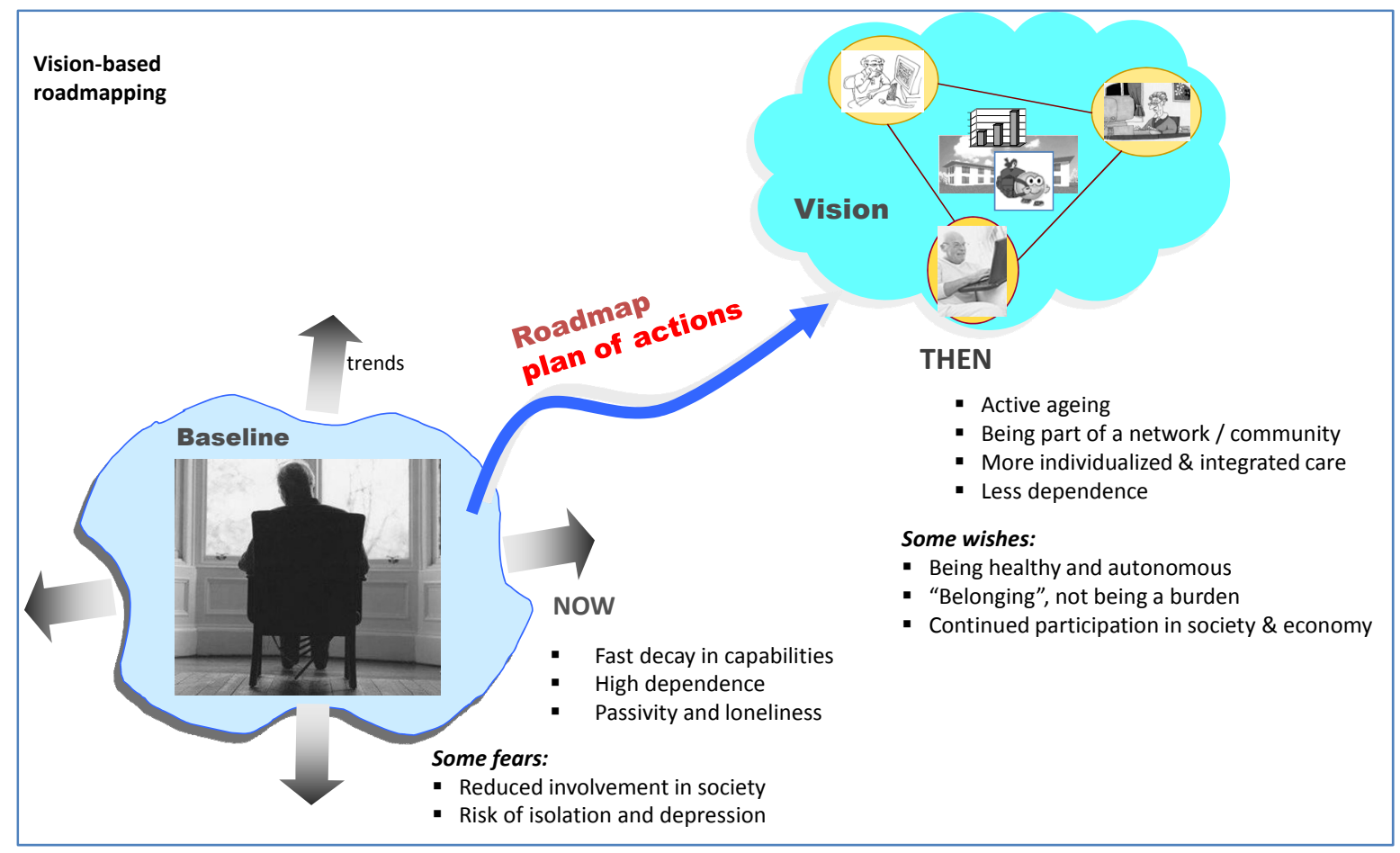

Figure 1. Components of a roadmap 


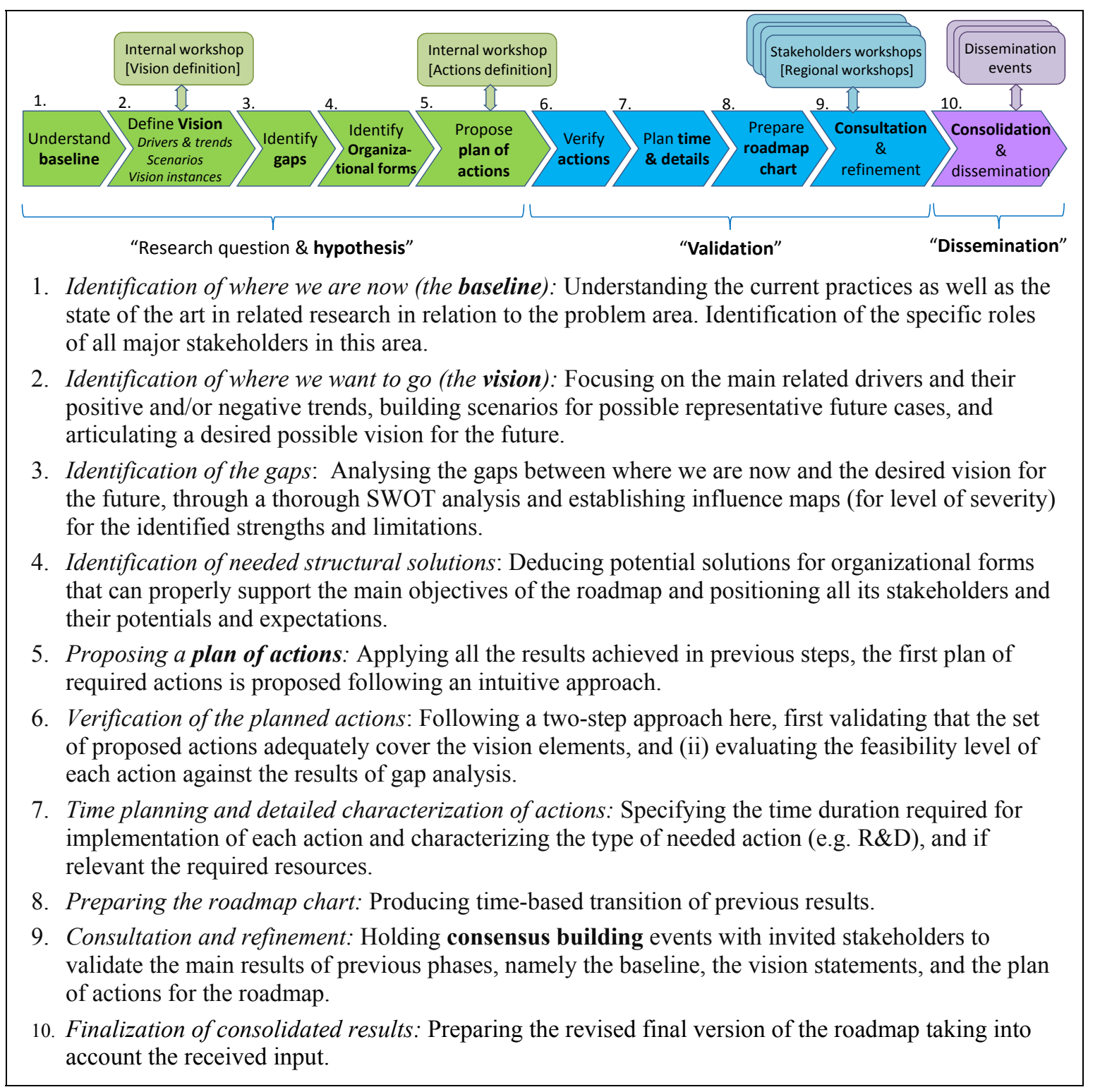

Figure 2. Roadmapping method

in various projects [15], [16], [17]. The rational in this approach is that contributions from stakeholders can better be collected and integrated if, prior to consensus building workshops, a small team elaborates a draft roadmap. This draft, representing a kind of "hypothesis", is then used to focus discussions with stakeholders.

The team in charge of the process in the case of the BRAID roadmap was formed by Queen's University Belfast; Centre for Science, Society and Citizenship; Trilateral Research \& Consulting; Global Security Inc.; University of Tasmania; Uninova Institute / New University of Lisbon; Universiteit van Amsterdam; Netwell Centre, Dundalk Institute of Technology; and VDI/VDE Innovation +
Technik Gmbh. In particular the vision elaboration part was led by the University of Amsterdam and the plan of actions by the Uninova Institute.

ICT and Ageing represents indeed a complex area that can be analysed from multiple perspectives and requires the contribution of multiple disciplines. In this work four perspectives or life settings are considered particularly relevant and selected as the basis for focused consideration in the various phases of the roadmapping process:

- Independent living - how technology can assist in normal daily life activities e.g. tasks at home, mobility, safety, agenda management (memory help), etc. 
- Health and care in life - how technology can assist in health monitoring, disease prevention, and compensation for disabilities.

- Occupation in life - how technology can support the continuation of professional activities along the ageing process.

- Recreation in life - how technology can facilitate socialization and participation in leisure activities.

As such, all components of the roadmap are instantiated into each of these life settings.

\section{Baseline, Vision and Gap Analysis}

As expressed in the adopted method, previous to the elaboration of a plan of actions, it is necessary to understand the baseline, elaborate a vision statement and proceed with a gap analysis. The study of the state of the art (baseline) in BRAID was informed by the findings of previous roadmapping projects, namely AALIANCE, CAPSIL, ePAL, and SENIOR, complemented with extensive literature survey and discussions with stakeholders. This process ended with a synthesis of what is found to be currently the main positive or supporting elements as well as the negative or limiting ones regarding all life settings, as illustrated in Table 1 for the case of Independent Living.

The vision statement for BRAID provides a direction where the society shall strive to take, in order to support its ageing citizens in different areas of their life. A vision defines a

Table 1. Supporting and limiting elements regarding Independent Living

\section{Supporting elements:}

S1 Base ICT infrastructures - broadband Internet and mobile computing - exist across Europe to provide the basic communication building blocks that will be needed to implement the vision

S2 Progress on smart homes and Internet of Things development opens new opportunities for developing services for home safety and care

S3 A large panoply of mechanisms and tools for safe communications (including cryptography), user identification and authentication (including biometric systems), access / visibility rights definition and control have been developed

S4 Developments in ICT supporting localization, driving assistance, route planning, inter-modal mobility including services integration (e.g. integrated public transports) are growing

S5 Significant progress in sensing and monitoring technologies, and ICT for home safety, care, and personal activity management, including context awareness reasoning

S6 Progress on assistive services for daily living assistance, telecare, and early experiments on preventing cognitive decline

S7 Progress on technological standardization and interoperability, facilitating the development of more integrated care services

S8 Some experiments on companion robots offer a clearer understanding of current limitations of advanced robotics in elderly care.

\section{Limiting elements:}

L1 Fast proliferation of new tools and functionalities without a holistic approach, an obstacle for adoption by seniors

L2 Assistive and adaptive technologies for elderly cognitive assistance, daily life assistance, home safety, wellness and health monitoring still lacks significant base multi-disciplinary research

L3 Reasoning and context awareness systems for the autonomous daily life assistance are still very complex to develop

L4 Service, companion, and care-taking robots still encounters both scientific, economic and social challenges

L5 Actual social welfare structures are not prepared for the increase of life expectance and corresponding demographic growth

L6 Integration and configuration of mechanisms and tools for security and privacy are still difficult, both at technological and regulatory levels

L7 Lack of adoption of ICT to establish collaborative communities / social networks in support of independent living of elderly citizens

L8 In spite of previous developments, assistive services are still predominantly fragmented

L9 The real impacts and success/acceptance factors of novel approaches to AAL are not known

L10 Life-long learning namely regarding new ICT is still not keeping pace with new technologies. 
desired future, while strongly interconnected with the framework that underlies the organizations or societies [14]. A fundamental prerequisite for developing a vision for the desired future for active ageing is to identify both: the key drivers (i.e. the main driving core values and core purpose. Core values are the essential and enduring tenets of an organization or society. Core values have intrinsic value and importance to those inside the organization or society. Core purpose however points to certain fundamental reason

Table 2. General vision statement for ICT and Ageing

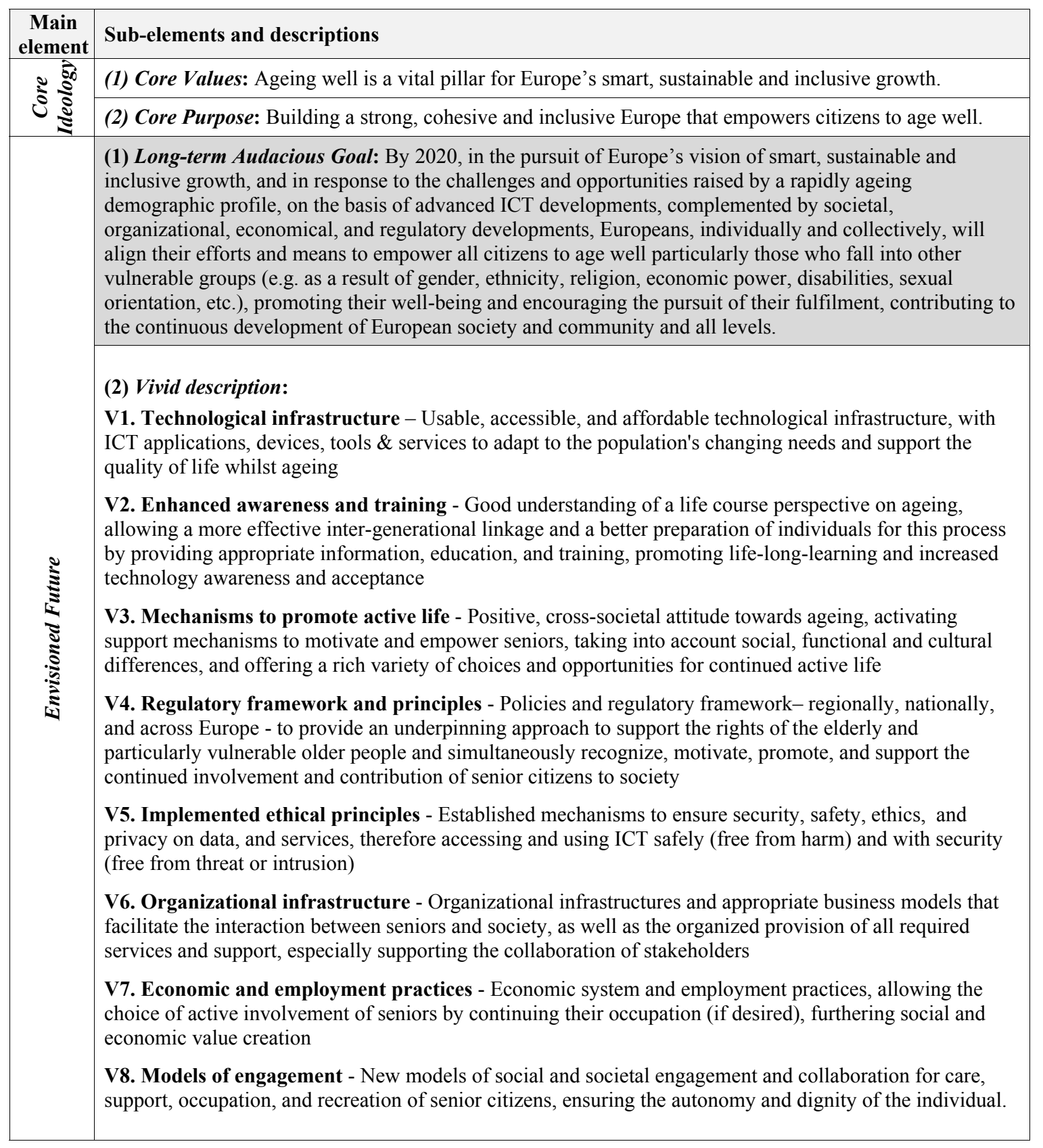

forces in the market and society) and their related trends regarding the BRAID environment. A well-conceived vision consists of two major components, namely, the core ideology and the envisioned future [18]. Core ideology is the first primary component of the vision framework which consists of two parts: for society to exist. Envisioned future is the second primary component of the vision framework which consists of 2 parts: a longterm audacious goal and a vivid description or desired facets of what it will be like when goals are achieved. Table 2 shows the established vision for BRAID. 
In addition to the overarching core vision for BRAID, four instantiations of it, one for each of the life settings, are developed (Figure 3). This instantiation approach is applied because capturing all the aspects and perspectives which are relevant to the BRAID environment within one vision statement encompassing one set of desired facets is too complex and presents a barrier to successful roadmap development and specification. The instantiation approach enables focusing down on specific aspects and relevant details for each of the four life settings.

Before trying to suggest a plan of actions, a systematic gap analysis needs to be conducted by comparing the vision with the current situation and perceived trends (baseline). Figure 4 illustrates the result of gap analysis for the Independent Living setting. The middle ovals in this influence map represent the desired facets of the vision; the upper rectangles represent the identified strengths or supporting elements and the lower rectangles the identified limitations in the current situation. The arrows represent the influences.

Since it is difficult to adopt a quantitative scale, a qualitative one (e.g. Strong, Average, and Moderate influence) is proposed for qualifying the level of influence of the baseline elements identified as supporting and limiting factors on the achievement of the vision facets. The expression of these influences is made on the basis that one "supporting element" is likely to have a positive effect on some of the vision facets. One "limiting element" on the other hand will have a negative influence on the achievement of some of the vision facets.

The influence maps developed for the various life settings provide a kind of qualitative analysis (and visual representation) of the state of potentials and barriers on the road to reach the vision. Therefore, these maps will help experts to observing how difficult or easy it is to achieve every vision facet, as well as serving as input to definition of an action plan.

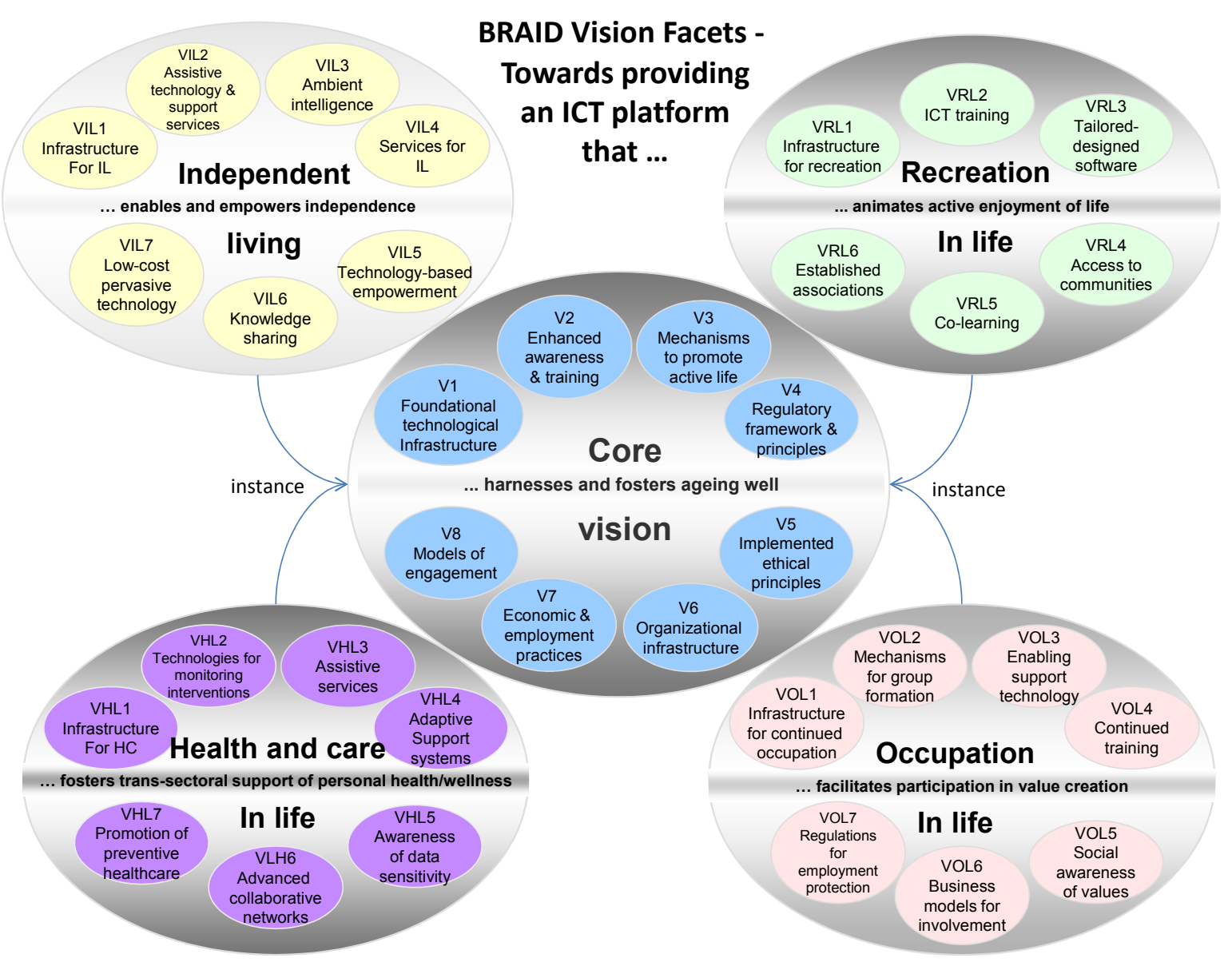

Figure 3. Main facets of BRAID vision and its instantiations 


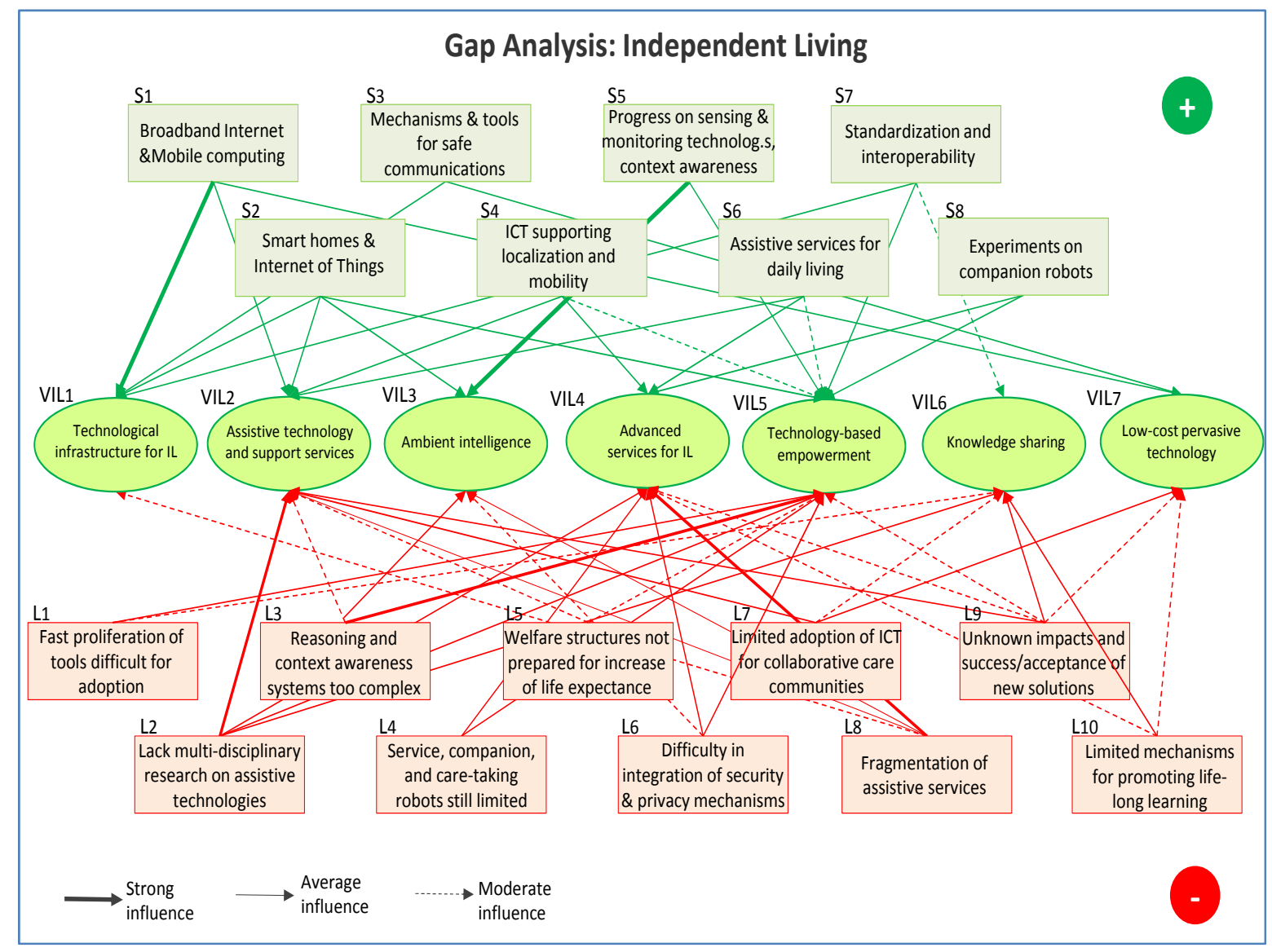

Figure 4. Gap analysis - example for Independent Living

\section{Proposed Plan of Actions}

After the gap analysis, and as a result of an extensive brainstorming, group discussion and consensus building among a variety of stakeholders, a set of strategic research actions are proposed. These actions are chosen in order to cover all stated facets of the vision (not necessarily a one-to-one correspondence between facets and actions), while being feasible considering the current situation (baseline) and trends, and taking into account the results of the gap analysis.

Four main groups of actions are organized around the life settings considered in BRAID: Independent Living, Health and Care in Life, Occupation in Life, and Recreation in Life. Furthermore, a set of general actions which span across all life settings is also introduced. The proposed actions are organized in two categories: actions related to ICT development and policy related actions or recommendations. Each of the proposed actions in ICT-related research is further detailed into a number of sub-actions.

The following sections introduce a brief description of the proposed strategic research actions.

\subsection{Independent Living actions}

Under this perspective we address how new technologies can assist elderly in their normal daily life activities e.g. tasks at home, mobility, safety, agenda (memory help), etc. Main proposed developments under this perspective are focused on assistance at home, namely for elderly living alone, which goes hand-in-hand with developments on smart homes. It includes services such as living status monitoring, with connection to care providers in case of any emergency, agenda manager to compensate for memory losses, companion and service robots, integration of intelligent home appliances, etc. Support outside home, namely in terms of mobility assistance, shopping assistance, and other daily life activities, is also considered. 
The following strategic research actions (Figure 5) aim at achieving BRAID's vision instantiated to this life setting:

"By 2020, senior citizens will be empowered to live a long, fulfilling, and independent life through support from technological, societal, organizational, economic, and regulatory mechanisms. These supports include facilitating access to relatives, carers and the community, and assisting with daily life activities, such as house-keeping, buying food, and personal hygiene care among others, and are underpinned by supports for mobility, transport, security and safety."
AI1.1 - Plan, organize and support management of formal care networks.

AI1.2 - Plan, organize and support informal care networks.

AI1.3 - Design and develop tools for composition of collaborative care services.

AI2. Extend capabilities. Investigate, develop and integrate intelligent functionalities to compensate diminishing cognitive and physical capabilities and to design and develop intelligent, user-centred, context-aware and self-adapting tools for personal assistance in planning and performing daily activities and facilitating societal participation.
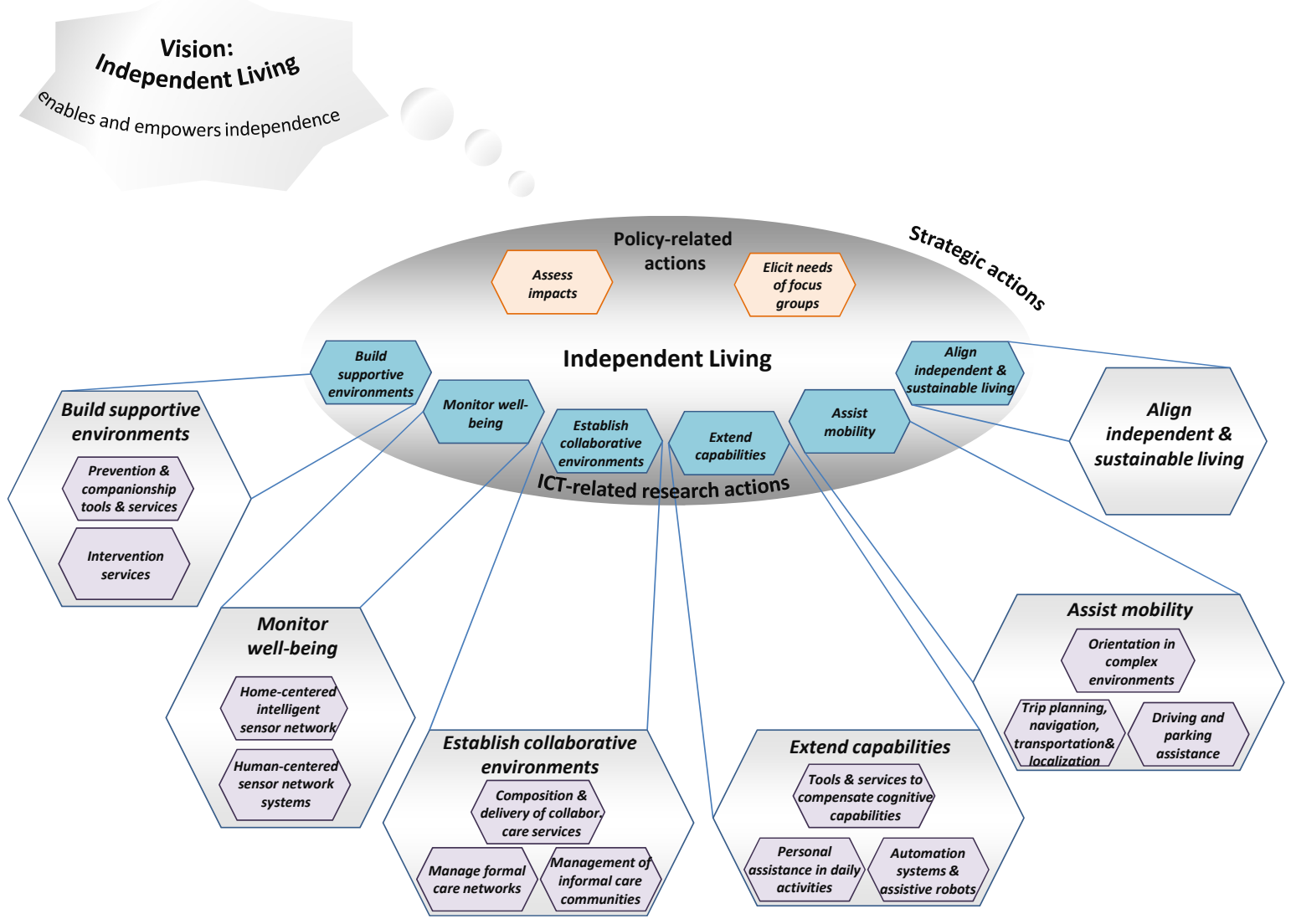

Figure 5. Detailed action plan for the Independent Living setting

\section{ICT-related research actions:}

AI1. Establish collaborative environments. Design and develop novel and effective collaborative environments, according to a design-for-all perspective, combining social networking and collaborative networks of care provision stakeholders to facilitate support, companionship, and community participation with trust establishment.
AI2.1 - Development of intelligent tools and services for personal assistance in daily activities.

AI2.2 - Development of automation systems and assistive robots.

AI2.3 - Investigate, develop and integrate intelligent tools and services to compensate diminishing cognitive capacities. 
AI3. Assist mobility. Integrate and customize methods and tools to assist mobility, including services for localization, trip planning, navigation, orientation in complex environments, driving assistance, and intermodal transportation, focusing elderly needs with special relevance on adequate and adaptable user interfaces, taking into account the built environment and issues of trust and safety.

AI3.1 - Integrate and customize methods, tools and services for trip planning, navigation and localization.

AI3.2 - Develop and customize driving and parking assistance.

AI3.3 - Integrate and customize methods, tools and services for orientation in "complex environments".

AI4. Monitor well-being. Design, develop and integrate open, affordable, and scalable sensor network environments both home-centred and human-centred, with intelligent monitoring, including new levels of security, safety, unintrusiveness and privacy towards supporting better caring services.

AI4.1 - Design, develop and integrate home-centred intelligent sensor network environments.

AI4.2 - Design, develop and integrate human-centred intelligent sensor network systems development.

AI5. Build supportive environments. Design, develop, and validate preventive and responsive interventions based on situational awareness, considering different contexts (e.g. at home, at work, outside), while trying to avoid creating dependency.

AI5.1 - Design and development of prevention and companionship tools and services.

AI5.2 - Design and development of intervention services.

AI6. Align independent and sustainable living. Explore the alignment of ICT for Independent Living with smart grid and sustainable development technologies, including interoperability concerns, with the aid of users and relevant stakeholders.

\section{Policy related actions:}

RI1. Assess impacts. Promote integrative studies on the sociological, economic, ethical, and quality of life impacts of introducing services and technologies for independent living.

RI2. Elicit needs of focus groups. Comprehensively characterize different focus groups, their needs, as well as facilitators, obstacles, and acceptability potential.

\subsection{Health and Care in Life actions}

This life setting addresses how technology can assist in health-related activities (remote health monitoring, emergency assistance, sensing environments, exercise assistance, prescription reminding, etc.).

The following strategic research actions (Figure 6) aim at achieving BRAID's vision instantiated to this life setting:

"By 2020, as a part of the ageing well paradigm, support for health and care (including physical and mental health, and prevention, diagnostics and treatment of sickness), will become a high priority strategy across Europe. The emerging health care technologies and services when applied to elderly shall be used in new ways in the society, across a distributed infrastructure focusing on decentralized models, while sensible to the ethical consequences of the introduced innovations and providing mechanisms for the protection of individual rights. Political / decision-making systems at national and local level, and public, commercial and not-for-profit organizations supporting healthcare will adapt to this new environment, considering the needs of the network of stakeholders, such as caregivers, family and friends."

\section{ICT-related research actions:}

AH1. Establish healthcare ecosystem. Define new organizational and business models, driven by affordability concerns, and develop support tools for the establishment of collaborative healthcare ecosystems involving families, healthcare providers, social security and regulatory authorities, forming the backbone for the emergence of new services for healthy living support, integrating formal and informal care.

AH1.1 - Plan, organize and support management of the healthcare ecosystem. 

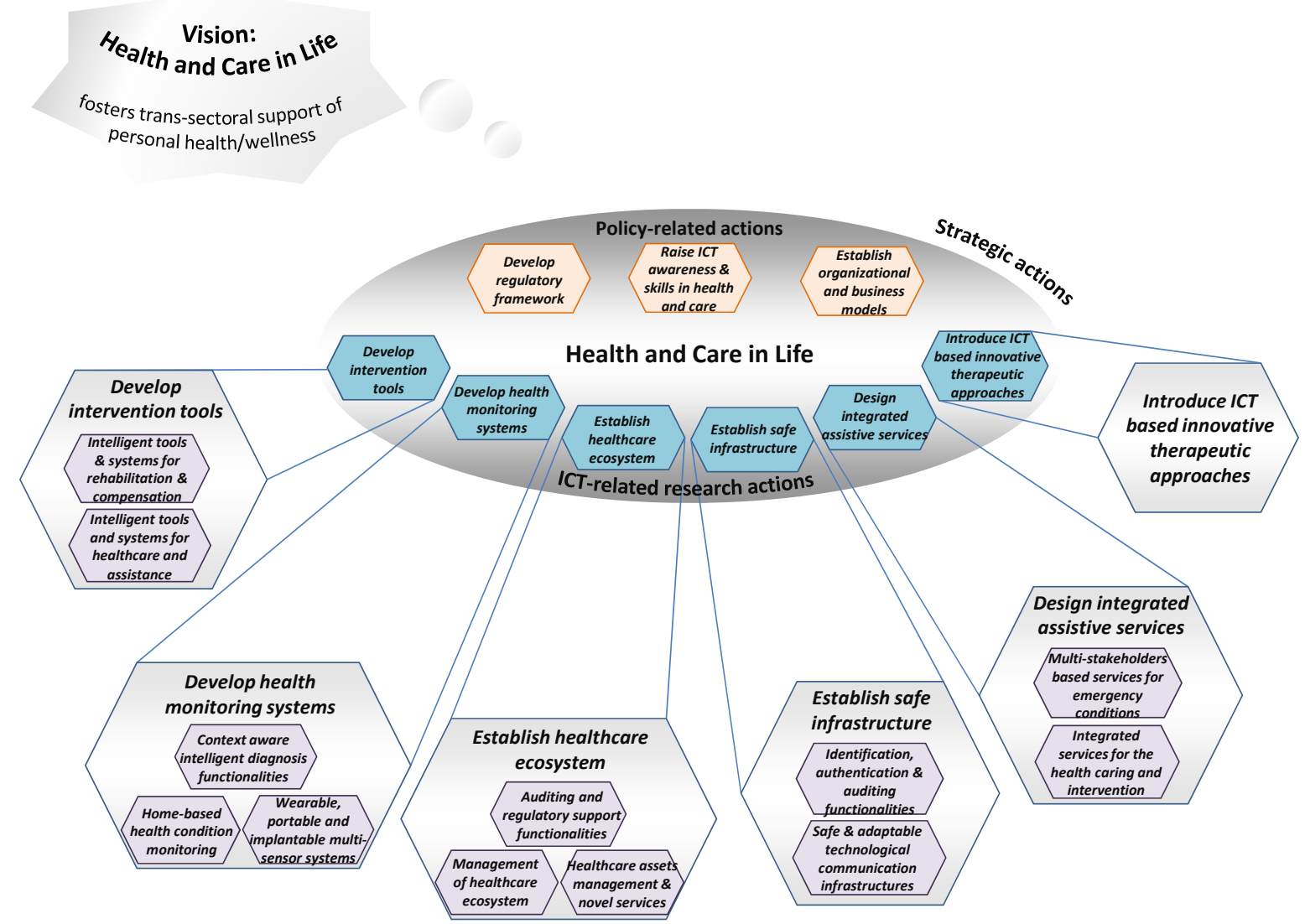

Figure 6. Detailed action plan for the Health and Care in Life setting

AH1.2 - Develop functionalities for healthcare assets management and emergence of novel services.

AH1.3 - Develop auditing and regulatory support functionalities.

AH2. Develop health monitoring systems. Design, develop and integrate affordable sensorial systems for health conditions monitoring, combined with intelligent diagnosis functionalities, understanding of the environment and other context factors, and easily adaptable to the needs of each senior individual and considering acceptability issues.

AH2.1 - Develop and integrate homebased health condition monitoring systems. AH2.2 - Develop wearable, portable and implantable multi-sensor systems.

AH2.3 - Design and develop context aware intelligent diagnosis functionalities.

AH3. Establish safe infrastructure. Develop a safe and adaptable infrastructure, aligned with relevant standards in e-health, to support the provision of consumer-driven healthcare services, including prevention and healthy life style assistance.
AH3.1 - Design and develop safe and adaptable technological communication infrastructures.

AH3.2 - Design and develop identification, authentication and auditing functionalities.

AH4. Design integrated assistive services. Create a multi-stakeholder framework for the emergence of integrated information-based assistive health care services, with particular emphasis on user-centred design, quality of service, and recipient's quality of life.

AH4.1 - Develop integrated services for the health caring and intervention.

AH4.2 - Dynamic configuration of multistakeholders based services in response to emergency conditions.

AH5. Develop intervention tools. Design, develop and assess advanced devices, intelligent robots, and intelligent tools to support home- and healthcare institution based interventions and associated support systems, like prevention systems, which are selfadapting to the cognitive, emotional, and physical status of the senior and respect the established safety and ethical principles. 
AH5.1 - Develop intelligent tools and systems for healthcare and assistance.

AH5.2 - Develop intelligent tools and systems for rehabilitation and disability compensation.

AH6. Introduce ICT based innovative therapeutic approaches. Exploring ICT to create novel therapeutic environments, support palliative care, cognitive and mental well-being, and promote healthy life styles. Issues like interoperability and affordability should be considered.

\section{Policy related actions:}

RH1. Raise ICT awareness and skills in health and care. Launch actions and develop mechanisms to increase the potential of ICT support for "healthy living environments" and to form a consensus on values, ethical principles, rights, safety and privacy issues, as well as a better understanding of the consequences of a shift towards getting health services at home.

RH2. Develop regulatory framework. Promote studies to elaborate, assess and regulate new organizational forms, legal structures and protocols for healthcare provision to ageing population from a multi-sectorial collaboration perspective.
RH3. Establish organizational and business models. Identify critical elements in ICT-based support services for healthy living, taking into account all the potential actors and stakeholders, and promote the design of sustainable business models.

\subsection{Occupation in Life actions}

This perspective addresses how technology can support the continuation of professional activities. The life setting of occupation in life can look very different for individuals, depending on the background work structure, sector, individual goals, capabilities, flexibility, opportunities, and functional ability. It covers both pre-retirement and post-retirement activities. In fact, in face of economic crisis and the growing pressure on the pension systems, it is likely that the notion of retirement as an abrupt event will change in the coming years. This setting includes both voluntary and paid work.

The following strategic research actions (Figure 7) aim at achieving BRAID's vision instantiated to this life setting:

"By 2020, due to the ageing population in Europe, an opportunity and need will arise to
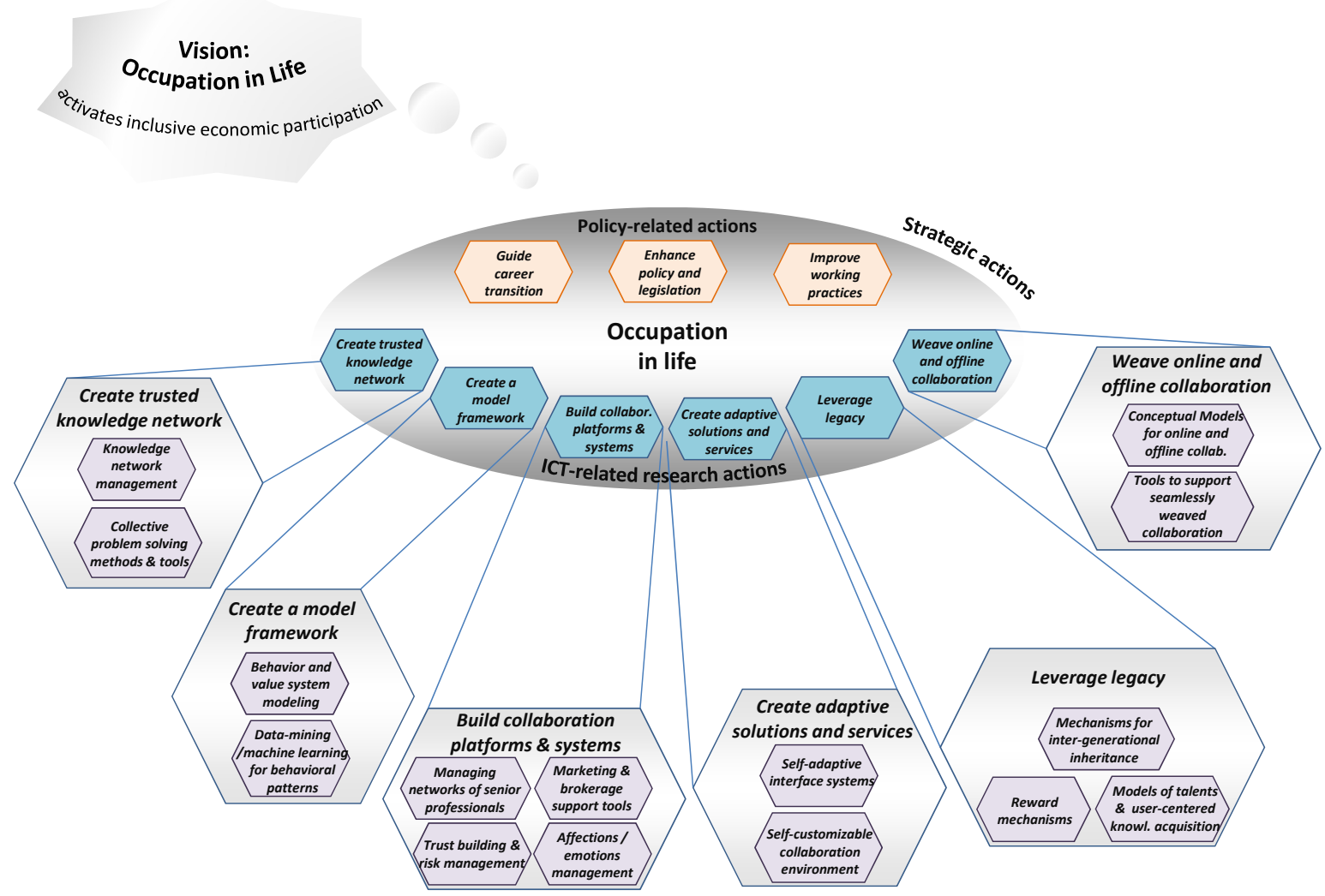

Figure 7. Detailed action plan for the Occupation in Life setting 
create a new framework for a model of work selected by seniors and adapted as they age, enabling them, if desired, to earn a living or perform voluntary work, through continued employment or have some form of continued work engagement. This framework will require support for its technological, socioorganizational, legal and political aspects. The aimed vision capitalizes on the talents and expertise of senior workers, facilitating value creation through the use of ICT for the benefit of the individual, the economy and European society as a whole."

\section{ICT-related research actions:}

AO1. Build collaboration platforms and systems. Design and develop open ICT collaboration platforms, support, and systems aimed at facilitating value creation, addressing the specific needs of communities of senior professionals, and which promote intergenerational interaction and socialization, which are enhanced by affective computing, context awareness, and trust establishment.

AO1.1 - Develop advanced functionalities and systems for management of networks of senior professionals.

AO1.2 - Develop marketing and brokerage support tools for communities of senior professionals.

AO1.3 - Develop trust building and risk management systems for communities of senior professionals.

A01.4 - Develop affections / emotions management systems for communities of senior professionals.

AO2. Leverage legacy. Develop environments that empower and enable seniors to create a legacy capitalizing on their invaluable and transferable personal / professional knowledge and experience.

AO2.1 - Define conceptual models of talents and develop user-centred knowledge acquisition tools.

AO2.2 - Create reward mechanisms (system of incentives) to attract usergenerated knowledge.

AO2.3 - Mechanisms to promote intergenerational inheritance.

AO3. Create adaptive solutions and services. Develop and integrate self-adaptive and configurable technology solutions and services in ICT environments, applying principles of e- accessibility, design for all, and usability in order to facilitate technology acceptance and enable customization for/by seniors.

AO3.1 - Develop self-adaptive interface systems.

AO3.2 - Develop self-customizable collaboration environments and services.

AO4. Create a model framework. Develop approaches, models, and reasoning methods related to older people's occupation life cycle and their participation in the economic system, including value systems, behaviours, and issues of physical, cultural and emotional health.

AO4.1 - Develop a conceptual base for behavioural and value system modelling.

AO4.2 - Develop data-mining / machine learning approaches for behavioural patterns discovery.

AO5. Create trusted knowledge networks. Create a trusted knowledge network that provides an integrative framework to enable seniors within their occupation in life, whether professional or voluntary.

AO5.1 - Develop effective knowledge network management systems

A05.2 - Develop collective problem solving methods and tools

AO6. Weave online and offline collaboration. Develop integrative framework for identity management which effectively and seamlessly joins online and offline collaboration, for seniors, to create invaluable connections between virtual and real-world aspects of their occupation in life, namely when keeping the links with former employers.

A06.1 - Develop conceptual models for online and offline collaboration.

A06.2 - Develop tools to support seamlessly weaved online / offline collaboration.

\section{Policy related actions:}

RO1. Guide career transition. Define new lifelong training programs and realistic practices that prepare for and guide the successful transition of senior knowledge holders from full employment to occupation in life.

$\mathrm{RO}$. Improve working practices. Investigate new models of working practices and related reward and taxation models for seniors, taking account of work-life balance, aging well and 
gender, and promote the findings to positively influence societal perception of older workers, also considering existing standards.

RO3. Enhance policy and legislation. Identify and assess current national and European policy, legislation and incentives relevant to active participation of seniors in the socioeconomic system and recommend new approaches that lower barriers and promote and support active aging according to cultural issues. Evaluation of the impact on society resultant of older peoples' engagement should be considered.

\subsection{Recreation in Life actions}

This life setting addresses how technology can facilitate socialization and participation of ageing citizens in social, leisure, learning, and even religious, cultural and political activities.

The following strategic research actions (Figure 8) aim at achieving BRAID's vision instantiated to this life setting:

"By 2020, ageing citizens will increase their pursuit of active recreational lifestyles that suit their abilities and preferences, which creates new opportunities for innovative supporting products and services. Recreation is seen as a broad set of activities involving peoples' participation and enjoyment in cultural life, craft, hobbies, sport and physical activity, entertainment, socializing, travel \& leisure, political engagement, spiritual and faith groups, life-long learning, passing on personal wisdom, history and experience, keeping pets, and playing games. Active recreational interests and lifestyles may improve mental well-being, and have a positive effect on the physical health and well-being of seniors. New technology solutions can support communications between seniors, families, friends, and peers, strengthening community participation and forming new communities and social networks with similar interests."

\section{ICT-related research actions:}

AR1. Build participatory communities. Design, develop and implement local and regional participatory communities that combine online and offline participation through social networking, inter-generational interaction, volunteering, and local government
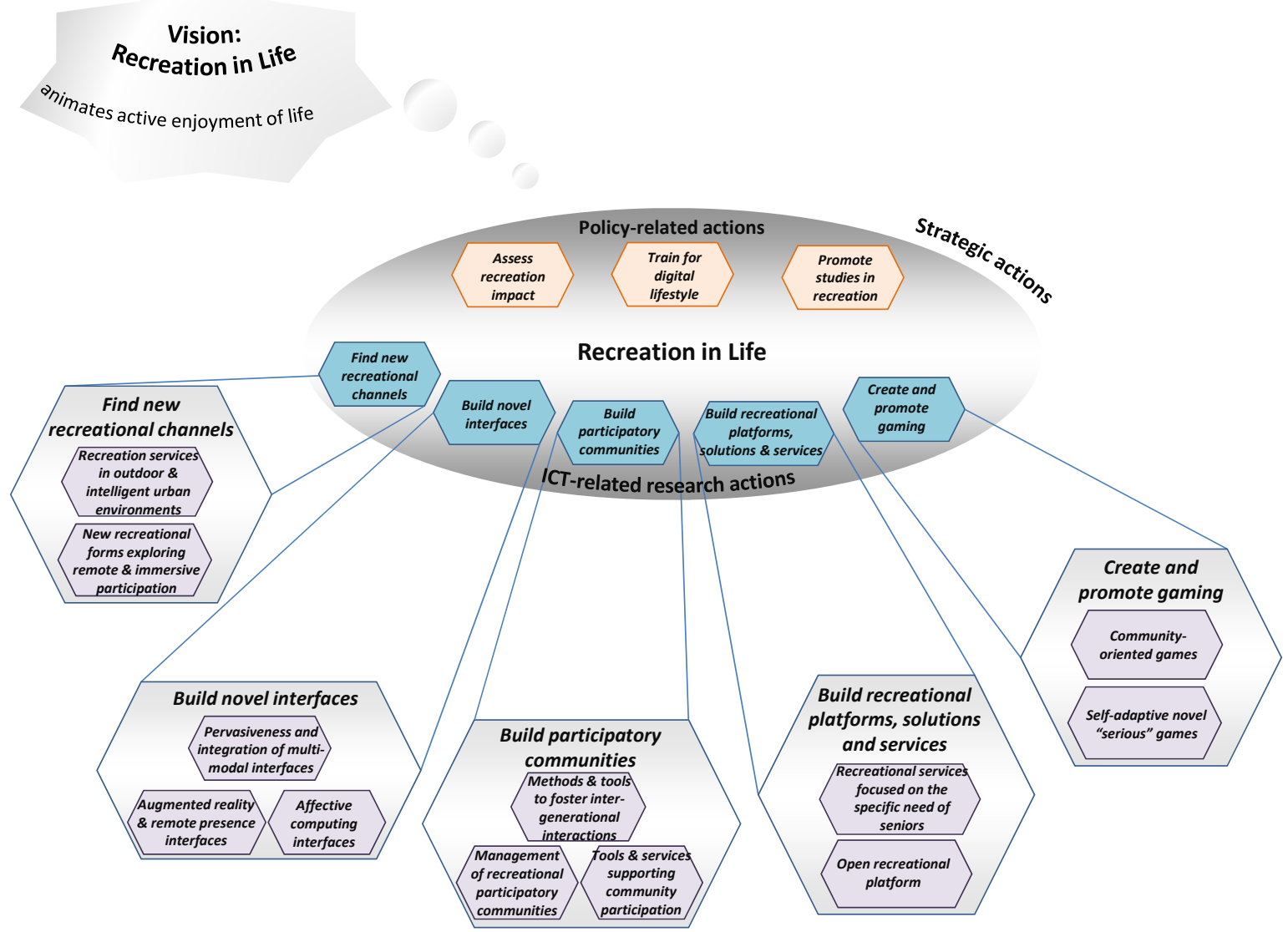

Figure 8. Detailed action plan for the Recreation in Life setting 
involvement, focusing on participatory recreational life and wellbeing.

AR1.1 - Plan, organize and support management of recreational participatory communities.

AR1.2 - Develop tools and services supporting community participation.

AR1.3 - Develop methods and tools to foster inter-generational interactions on a community basis.

AR2. Build novel interfaces. Develop novel human-machine interfaces with high quality of usability and applying design for all principles, oriented towards seniors' active engagement in recreational activities, considering their cognitive and physical capabilities, and including augmented reality, affective computing, companion artefacts, pervasiveness, multi-modal interfaces, etc.

AR2.1 - Explore augmented reality and remote presence interfaces.

AR2.2 - Develop affective computing interfaces.

AR2.3 - Develop methods to promote pervasiveness and integration of multimodal interfaces.

AR3. Build recreational platforms, solutions and services. Design and develop open, secure, interoperable, flexible, accessible, customizable and affordable ICT recreational platforms, solutions and services for senior citizens.

AR3.1 - Design and develop an open recreational platform.

AR3.2 - Customize and integrate recreational services focused on the specific needs of seniors.

AR4. Find new recreational channels. Elaborate innovation portfolio of new ICTsupported recreational activities for seniors, exploring tele-presence, augmented reality and immersive technologies, remote participation in cultural events, collaborative gaming, intelligent urban environments, etc. All these should consider cultural aspects.

AR4.1 - Design and develop new recreational forms exploring remote and immersive participation.

AR4.2 - Novel technology assisted recreation services in outdoor and intelligent urban environments.

AR5. Create and promote gaming. Design, develop and promote novel physical, recreational and cognitive games for seniors, serious games dynamically responsive to user's physiological and affective state, and integrated physical-cognitive gaming, with a holistic focus on recreation, wellbeing, socialization, and inter-generational collaboration.

AR5.1 - Design and develop self-adaptive novel "serious" games.

AR5.2 - Design and develop communityoriented games.

\section{Policy related actions:}

RR1. Train for digital lifestyle. Create and deploy training programs and mechanisms oriented to help senior citizens enter and explore new lifestyles in the digital age, with particular attention to rural areas.

RR2. Assess recreation impact. Promote multidisciplinary studies on the impact of physical and cognitive recreational activities for seniors, either in urban or rural contexts.

RR3. Promote studies in recreation. Promote studies on all aspects of ICT-enabled/induced social innovation oriented to participatory involvement of elderly in recreational, cultural and social life. One challenging result is the creation of taxonomies for understanding the activities that are important for the elderly well-being.

\subsection{General Actions}

The following actions (Figure 9) span horizontally over the four life settings, being of

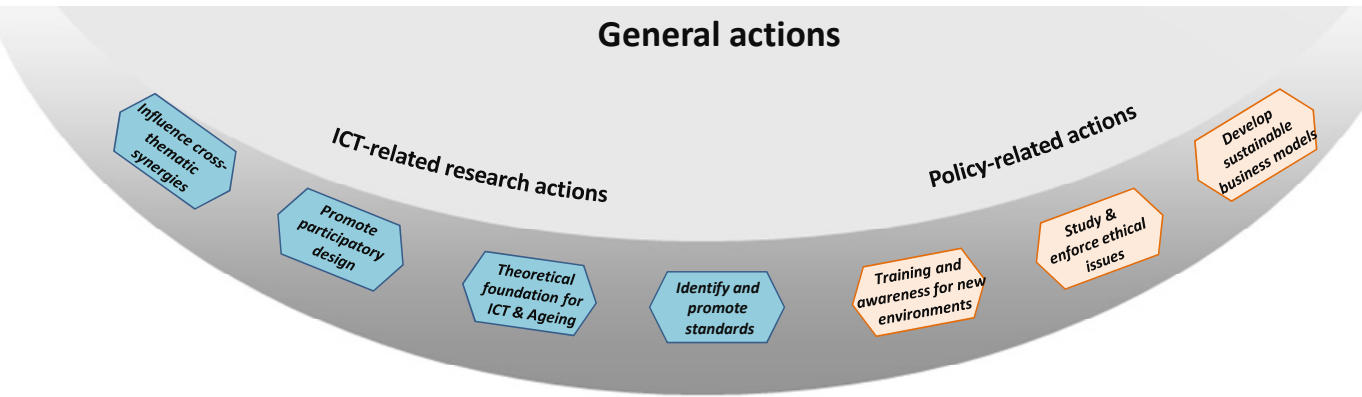

Figure 9. General Actions plan 
a more general nature, but an essential complementary plan to help reaching the vision established for those settings.

\section{ICT-related research action:}

AG1. Identify and promote standards. Assess existing standards, promoting adoption of the most promising ones, and monitor mature technological research and development results towards promoting their standardization, in order to facilitate wider take-up, interoperability and affordability of solutions.

AG2. Develop theoretical foundation for ICT and Ageing. Contribute to establish a sounder scientific basis for ICT and Ageing R\&D, integrating contributions from a multidisciplinary nature and promoting a consolidation of concepts and common ontologies.

AG3. Influence cross-thematic synergies. Identify and promote technological development synergies between ICT and Ageing and other focus areas, e.g. impact on the construction and building procedures, synergies with intelligent transport systems, synergies with smart grid infrastructures development, etc.

AG4. Promote participatory and inclusive design. Identify suitable approaches and promote pilot experiments on the involvement of seniors in the processes of co-designing systems for ICT and Ageing.

\section{Policy related actions:}

RG1. Training and awareness for new environments. Define new community-based training programs leveraging the potential of new technology-based assistive environments.

RG2. Study and promote ethical issues.
Promote studies on the ethical implications of ICT and Ageing in all life settings and devise practical mechanisms to enforce the adherence to ethical principles.

RG3. Develop and promote sustainable business models. Elaborate and promote business models supporting ICT and Ageing solutions in all life settings, focusing on affordability and sustainability under different economic scenarios.

\section{Roadmap Validation}

As described in the roadmapping method, the proposed strategic actions plan resulted from a multi-stage construction and validation process. An initial formulation (similar to the research hypothesis in the traditional scientific research method) was prepared by the BRAID consortium following a series of internal workshops and brainstorming sessions. Once a set of strategic actions emerged as a result of the brainstorming exercise, it was then necessary to proceed with a verification of those actions. The adopted verification approach, at the early stages of the roadmapping process, comprised two main activities [9], [15], [17]: (i) Verify that the proposed actions adequately cover all facets of the vision; and (ii) Assess the feasibility of each action considering the results of the gap analysis. Figure 10 illustrates the first step of validating the roadmap results for the action AI1 under the Independent Living perspective.

Regarding the second step of validation, related to feasibility, the adopted approach was to consider how the supporting and limiting elements at European level, identified in the gap analysis, are likely to facilitate or make difficult the implementation of each action.

Vision facet $\longleftarrow$ covers Action

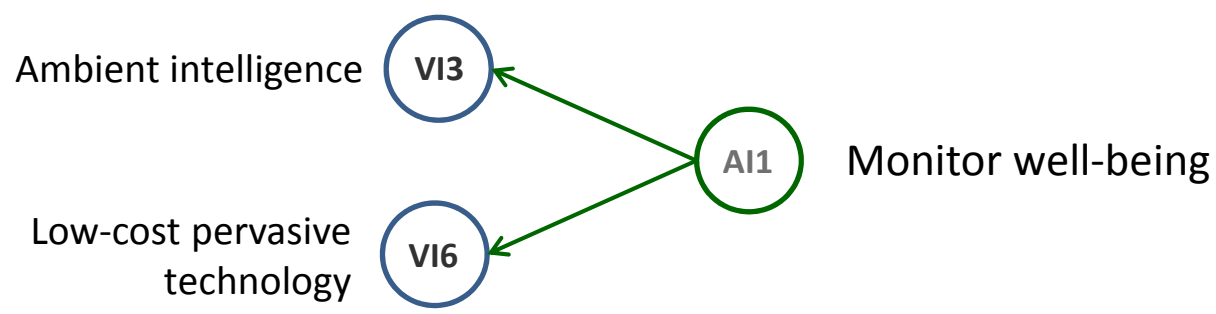

Figure 10. Covering the vision facets - an example 
Figure 11 illustrates the assessment of the feasibility of action AI1 under the Independent Living perspective. This verification needed to be conducted by experts and depends on the perception of each individual according to his/her background knowledge. Therefore a qualitative scale (scale: Moderate, Hard, Very Hard) was adopted. The colour codes also indicate how strongly the gap analysis elements affect the implementation of the action (darker colour meaning a stronger influence).

\begin{tabular}{|c|c|}
\hline 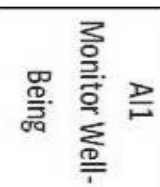 & \\
\hline & $\begin{array}{l}\text { S1 - Broadband Internet \&Mobile } \\
\text { computing }\end{array}$ \\
\hline & $\begin{array}{l}\text { S2-Smart homes \& Internet of } \\
\text { Things }\end{array}$ \\
\hline & $\begin{array}{l}\text { S3- Mechanisms \& tools for safe } \\
\text { communications }\end{array}$ \\
\hline & $\begin{array}{l}\text { S4. ICT supporting localization } \\
\text { and mobility }\end{array}$ \\
\hline & $\begin{array}{l}\text { S5- Progress on sensing \& } \\
\text { monitoring technologies, context } \\
\text { awareness }\end{array}$ \\
\hline & $\begin{array}{l}\text { S6-Assistive services for daily } \\
\text { living }\end{array}$ \\
\hline & $\begin{array}{l}\text { S7- Standardization and } \\
\text { interoperability }\end{array}$ \\
\hline & $\begin{array}{l}\text { S8- Experiments on companion } \\
\text { robots }\end{array}$ \\
\hline & $\begin{array}{l}\text { L1-Fast proliferation of tools } \\
\text { difficult for adoption }\end{array}$ \\
\hline & $\begin{array}{l}\text { L2-Lack multi-disciplinary } \\
\text { research on assistive techn.s }\end{array}$ \\
\hline & $\begin{array}{l}\text { L3- Reasoning and context } \\
\text { awareness systems too complex }\end{array}$ \\
\hline & $\begin{array}{l}\text { L4-Service, companion, and care- } \\
\text { taking robots still limited }\end{array}$ \\
\hline & $\begin{array}{l}\text { L5- Welfare structures not } \\
\text { prepared for increase of life } \\
\text { expectance }\end{array}$ \\
\hline & $\begin{array}{l}\text { L6- Difficulty in integration of } \\
\text { security \& privacy mechanisms }\end{array}$ \\
\hline & $\begin{array}{l}\text { L7- Limited adoption of ICT for } \\
\text { collaborative care communities }\end{array}$ \\
\hline & $\begin{array}{l}\text { L8-Fragmentation of assistive } \\
\text { services }\end{array}$ \\
\hline & $\begin{array}{l}\text { L9- Unknown impacts and } \\
\text { success/acceptance of new } \\
\text { solutions }\end{array}$ \\
\hline & $\begin{array}{l}\text { L10- Limit, mechanisms to } \\
\text { promote life-long learning }\end{array}$ \\
\hline $\begin{array}{l}\frac{3}{\circ} \\
\frac{2}{0} \\
\frac{\mathfrak{D}}{\mathfrak{D}}\end{array}$ & FEASIBILITY \\
\hline
\end{tabular}

Figure 11. Assessing feasibility - an example
The next phase was focused on the refinement and consensus-building among relevant stakeholders. For this purpose, a number of Consensus Building Events were organized in different regions of Europe (Spain, Italy, Denmark, Ireland, and Hungary), complemented with a special conference session in Brazil and a final conference in Prague, Czech Republic. More than 150 stakeholders and experts from different backgrounds were involved in the validation process. This phase involved extensive discussion, collecting suggestions for amendment, and integration of all received feedback (Figure 12). The version included in Section 4 represents the consolidated result.

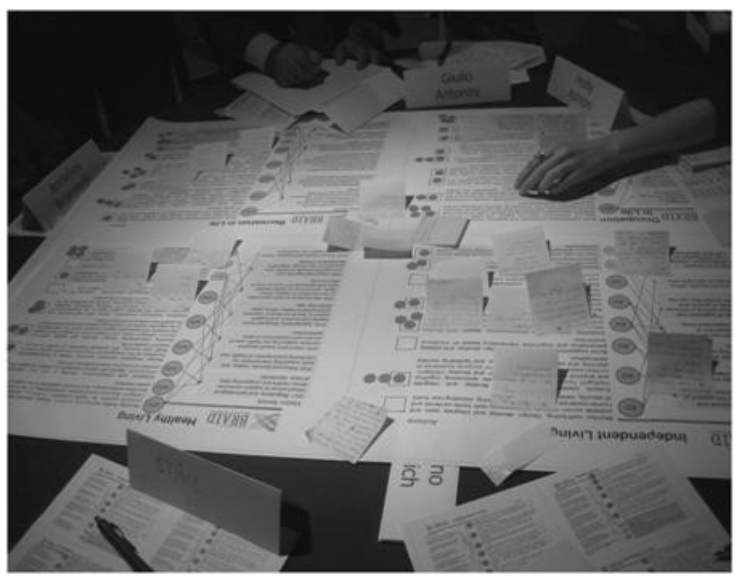

Figure 12. Consensus building events - Feedback in post-its and Voting

Stakeholders were also asked to vote in order to establish a prioritization of actions. Figure 13 shows the identified priorities for the actions in each life setting. The size of each box is proportional to the corresponding number of votes.

\section{Collaborative Networks Approach}

As reflected in the proposed plan of actions, and clearly identified during the interactions with stakeholders from different regions of Europe, there is a need to shift from a situation characterized by fragmented or decoupled services provided by single or loosely coupled organizations, to integrated care services that are the result of collaboration among various stakeholders. The consolidation of the concept of integrated care as part of the health policy reform across Europe also points in the same direction [19], [20]. The development of high quality and sustainable support services to ageing well requires a stronger engagement and 


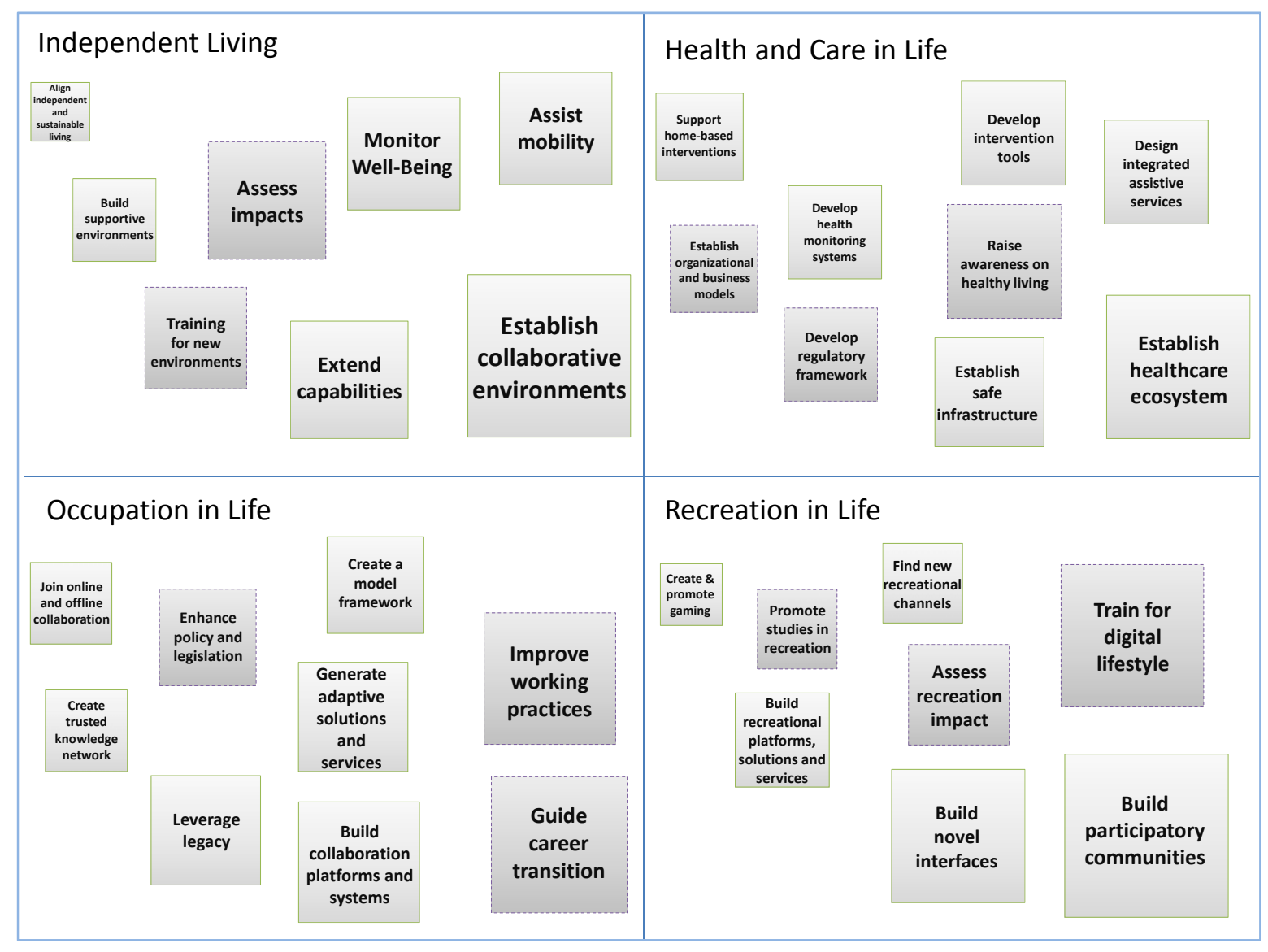

Figure 13. Prioritization of actions

collaborative effort among all relevant stakeholders, including local communities, leading to the concept of care ecosystems. As such, the next research stage on ICT and Ageing needs to seek strong interaction with the scientific discipline of collaborative networks.

Benefiting from advances in Internet technologies, there is a growing trend in industry and services to seek synergies through the participation in networks. Advances in the ICT area have enabled new forms of collaboration and induced the emergence of new paradigms, such as extended enterprise, virtual enterprise (VE) / virtual organization (VO), and professional virtual community, all representing temporary alliances of entities that come together to share their skills, core competencies and resources in order to better respond to emerging business opportunities or social needs, and whose collaboration is supported by computer networks.

Aiming to capture the essence of these and many other "manifestations" of networks and providing a new theoretical framework to support further developments, Collaborative Networks (CNs) emerged as a new scientific discipline [21]. CNs are complex systems featuring many facets, whose proper understanding requires contribution from multiple disciplines. In fact, the various manifestations of this paradigm have been studied by different branches of science, including computer science / computer engineering, management, economy, sociology, industrial engineering, law, etc. During the last 15 years a large number of $R \& D$ projects contributed to establish technological foundations as well as some operating practices for the support of different forms of CNs. This effort is particularly visible in Europe, namely through the various research programs sponsored by the European Commission, but also in the USA and other regions (Australia, Brazil, Japan, Mexico, to name a few). As a result of these initiatives, a large number of outcomes, including conceptual and reference models, platforms and tools, practices and governance models, are already available [22], constituting a potentially important baseline for 
the implementation of the next generation of elderly care services.

As implicit in the naming of many of the proposed strategic actions, the idea of collaborative networks for provision of integrated care and assistance services is strongly present in the BRAID roadmap. Also as reflected in Figure 13, the actions identified with the highest priority level in each life setting, are the ones that clearly imply a collaborative approach in service delivery. Complementarily, the prioritization of actions also shows that the successful deployment of solutions, with increased chances of acceptance by users, requires a shift from pure technocentric approaches, still prevalent in many initiatives, to a proper combination of ICT research with policy related actions. In brief:

- Independent living. As it can be observed in the proposed action plan, there is an aim to evolve towards more integrated services, involving multiple stakeholders, through well-coordinated collaborative communities / ecosystems. This can be addressed at community level - social networking, re-enforcing community links, reducing loneliness, exchanging support through time banks, etc. - or at the specialized care provision level through collaboration among diverse stakeholders care providers, health care centres, ambulance services, social security departments, NGOs, etc. At the mobility assistance level, and in alignment with current trends in advanced transport infrastructures, collaboration among multiple stakeholders is also needed - e.g. transport operators, traffic management entities, toll operators, parking lot operators, and other service providers. Finally, at the home infrastructure level, and as we progress towards more intelligent appliances and subsystems, collaborative networks principles and mechanisms can provide a better framework for systems integration (a new perspective for cyber-physical systems).

- Health and care in life. Also for this life setting, the role of collaborative networks can be identified in some of the proposed actions: Actions $\mathrm{AH} 1$ and $\mathrm{AH} 4$ clearly identify the need for collaborative healthcare ecosystems as enablers for the emergence of novel integrated healthy living support services. This should be complemented with appropriate regulatory frameworks and business models (RH2 and RH3). Principles and mechanisms developed in the collaborative networks area can also bring important contributions to the safe infrastructures supporting health monitoring ( $\mathrm{AH} 2$ and $\mathrm{AH} 3)$. For instance, the "establishing the healthcare ecosystem" action aims at defining new organizational and business models, driven by affordability concerns, and developing support tools for the establishment of collaborative healthcare ecosystems involving families, healthcare providers, social security and regulatory authorities, forming the backbone for the emergence of new services for healthy living support, integrating formal and informal care.

- Occupation in life. The creation of collaborative networks to facilitate the continuation of the involvement of seniors in the socio-economic system and to leverage their value creation potential is explicitly addressed in actions AO1, AO5, and AO6. In particular, the integration of existing communities of senior professionals with other existing networks (e.g. SME networks) constituting some novel forms of hybrid collaborative networks, need to be explored. The lack of such integration has led to some ghettoization of associations of senior professionals [17], [23].

- Recreation in life. Although many elderly social networks, focused on their socialization, have emerged in the last years, the proposed action plan aims at promoting the development of participatory, and thus collaborative, communities. Through these networks senior citizens can actively engage in community activities, inter-generational interactions and joint recreation initiatives. Collaborative gaming is another relevant direction, focused both on novel games for seniors - aiming at stimulating and preserving their cognitive capabilities - and games designed for inter-generational interaction and re-enforcement of family links. These actions require novel models and technology development, as well as new policies and regulatory frameworks. 
- General actions. Also some of these actions can benefit from concepts and approaches developed in the collaborative networks area.

Although the above examples are mostly focused on the ICT-related research actions, the consideration of collaborative networks aspects can also benefit the policy-related actions. This is particularly obvious in the cases of impact assessment, establishment of organizational and business models, and training actions.

\section{Implementation Issues}

The last phase of the roadmapping process was focused on the development of the implementation plan for the proposed research agenda. Regarding implementation modalities, three cases are considered, in line with the European Commission programs:

$R \& D$ projects - focusing on fundamental research and prototype development, aimed at addressing longer term challenges.

Pilot development projects - oriented towards the development of pilots and validation scenarios that allow verification and refinement of the results of previous phase.

Take-up projects - aiming at large scale validation of new technologies and services, as a mechanism to facilitate their take-up by society.

Based on these modalities, and coping with the stakeholders' opinions collected in the consensus building workshops, an implementation schedule is proposed for each action. Figure 14 (next page) illustrates the proposed scheduling for the Health and Care in Life setting.

Similar plans for other groups of actions can be found in project reports [24].

\section{Conclusions}

A systematically elaborated vision-based roadmap constitutes an important instrument to guide further research and development in ICT and Ageing towards well accepted solutions that smoothly integrate within the socio- economic context, while taking advantage of novel technological developments. BRAID roadmap was developed with this purpose, proposing a plan of strategic research actions, covering both ICT-related research and policyrelated recommendations.

It is becoming widely recognized that further to ICT development, the design of new collaborative organizational structures represents a promising contribution to face the challenges of providing integrated care and assistance services to a rapidly growing percentage of aged population. As such, and after an initial phase in which many efforts were focused on the provision of single, nonintegrated services, current trends point to the need of more integrated services, which are likely to result from contributions of various stakeholders. For this new perspective, it is important to bring into this area the concepts, models and tools already developed in the collaborative networks discipline, which were, however, originally mostly focused on industry and other business applications. Adapting such results to the ICT and Ageing area will provide a basis for the development of sustainable care ecosystems.

The systematic roadmapping process behind BRAID roadmap as well as the extensive validation process involving a large community of stakeholders, are important factors for providing confidence in the adequacy of the proposed research agenda. Nevertheless, as normal in any "futures planning" initiative, a roadmap is a dynamic construct that needs to be periodically revised alongside its implementation, taking into account new trends as they inevitably emerge.

\section{Acknowledgements}

This work was funded in part by the European Commission through the BRAID project (FP7 programme). The authors also thank the contribution of their partners as well as the multiple stakeholders involved in the consolidation workshops. 


\begin{tabular}{|c|c|c|c|c|c|}
\hline & & 2013 & 2016 & 2019 & 2021 \\
\hline \multicolumn{6}{|l|}{ AH1 Establish healthcare ecosystem } \\
\hline \multirow{3}{*}{$\begin{array}{l}\text { AH1.1 Plan, organize and support } \\
\text { management of the healthcare } \\
\text { ecosystem. }\end{array}$} & $R \& D$ & & & & \\
\hline & Pilot & & & & \\
\hline & Take-up & & & & \\
\hline & & & & & \\
\hline $\begin{array}{l}\text { AH1.2 Develop functionalities for } \\
\text { healthcare assets management and } \\
\text { emergence of novel services. }\end{array}$ & $R \& D$ & & & & \\
\hline & & & & & \\
\hline \multirow{3}{*}{$\begin{array}{l}\text { AH1.3 Develop auditing and regulatory } \\
\text { support functionalities. }\end{array}$} & $R \& D$ & & & & \\
\hline & Pilot & & & & \\
\hline & Take-up & & & & \\
\hline \multicolumn{6}{|l|}{ AH2 Develop health monitoring systems } \\
\hline $\begin{array}{l}\text { AH2.1 Develop and integrate home- } \\
\text { based health condition monitoring } \\
\text { systems. }\end{array}$ & Take-up & & & & \\
\hline & & & & & \\
\hline \multirow{3}{*}{$\begin{array}{l}\text { AH2.2 Develop wearable, portable and } \\
\text { implantable multi-sensor systems }\end{array}$} & $R \& D$ & & & & \\
\hline & Pilot & & & & \\
\hline & Take-up & & & & \\
\hline \multirow{3}{*}{$\begin{array}{l}\text { AH2.3 Design and develop context } \\
\text { aware intelligent diagnosis } \\
\text { functionalities }\end{array}$} & $R \& D$ & & & & \\
\hline & Pilot & & & & \\
\hline & Take-up & & & & \\
\hline \multicolumn{6}{|l|}{ AH3 Establish safe infrastructure } \\
\hline \multirow{3}{*}{$\begin{array}{l}\text { AH3.1 Design and develop safe and } \\
\text { adaptable technological } \\
\text { communication infrastructures }\end{array}$} & $R \& D$ & & & & \\
\hline & Pilot & & & & \\
\hline & Take-up & & & & \\
\hline & & & & & \\
\hline \multirow{3}{*}{$\begin{array}{l}\text { AH3.2 Design and develop } \\
\text { identification, authentication and } \\
\text { auditing functionalities }\end{array}$} & $R \& D$ & & & & \\
\hline & Pilot & & & & \\
\hline & Take-up & & & & \\
\hline \multicolumn{6}{|l|}{ AH4 Design integrated assistive services } \\
\hline \multirow{3}{*}{$\begin{array}{l}\text { AH4.1 Develop integrated services for } \\
\text { the health caring and intervention }\end{array}$} & $R \& D$ & & & & \\
\hline & Pilot & & & & \\
\hline & Take-up & & & & \\
\hline \multirow{3}{*}{$\begin{array}{l}\text { AH4.2 Dynamic configuration of multi- } \\
\text { stakeholders based services in } \\
\text { response to emergency conditions }\end{array}$} & $R \& D$ & & & & \\
\hline & Pilot & & & & \\
\hline & Take-up & & & & \\
\hline \multicolumn{6}{|c|}{\begin{tabular}{|l|l|} 
AH5 Develop intervention tools & \\
\end{tabular}} \\
\hline & $R \& D$ & & & & \\
\hline AHS.I Develop intelligent tools and & Pilot & & & & \\
\hline & Take-up & & & & \\
\hline AH5.2 Develop intelligent tools and & $R \& D$ & & & & \\
\hline systems for rehabilitation and & Pilot & & & & \\
\hline disability compensation & Take-up & & & & \\
\hline AH6 Introduce ICT based innovative & & & & & \\
\hline therapeutic approaches & $R \& D$ & & & & \\
\hline & Pilot & & & & \\
\hline & Take-up & & & & \\
\hline RH1 Raise ICT awareness and skills in & & & & & \\
\hline health and care & $R \& D$ & & & & \\
\hline & Pilot & & & & \\
\hline & Take-up & & & & \\
\hline RH2 Develon regulatory framework & & & & & \\
\hline RH2 Develop regulatory tramework & $R \& D$ & & & & \\
\hline & Pilot & & & & \\
\hline & Take-up & & & & \\
\hline RH3 Establish organizational and business & & & & & \\
\hline models & $R \& D$ & & & & \\
\hline & Pilot & & & & \\
\hline & Take-up & & & & \\
\hline
\end{tabular}

Figure 14. Proposed implementation schedule for Health and Care in Life actions 


\section{REFERENCES}

1. AGUILAR, J. M.; CANTOS, J.; EXPOSITO, G.; GÓMEZ, P. (2004). The Improvement of the Quality Of Life for Elderly and Relatives through Two TeleAssistance Services: The Telecare Approach. In Proceedings of TELECARE 2004 Workshop - Tele-Care and Collaborative Virtual Communities, Porto, Portugal, pp. 73-85, INSTICC Press.

2. CAMARINHA-MATOS, L. M.; ROSAS, J.; OLIVEIRA; A. (2004). A Mobile Agents Platform for Telecare and Teleassistance. In Proceedings of TELECARE 2004 - Int. Workshop on Tele-Care and Collaborative Virtual Communities in Elderly Care, Porto, Portugal, INSTICC Press, pp 37-48.

3. COSTA, R.; NOVAIS, P.; COSTA, A.; NEVES, J. (2009). Memory Support in Ambient Assisted Living. In Leveraging Knowledge for Innovation in Collaborative Networks, IFIP AICT 307, pp 745-752, Springer: Heidelberg.

4. VONTAS, A.; PROTOGEROS, N.; MOUMTZI, V. (2009). Practices and Services for Enabling the Independent Living Of Elderly Population. In Leveraging Knowledge for Innovation in Collaborative Networks, IFIP AICT 307, pp 753-758, Springer: Heidelberg.

5. HANK, K. (2010). Societal Determinants of Productive Aging: A Multilevel Analysis Across 11 European Countries, European Sociological Review, May 2010.

6. GARLICK, S. ; SOAR, J. (2007). Human Capital, Innovation and the Productive Ageing: Growth and Senior Aged Health in the Regional Community through Engaged Higher Education, Annual AUCEA Conference, 2-4 July 2007, Alice Springs, Australia.

7. USDHHS (1997). Active Aging: A Shift in the Paradigm - Denver Summit of Eight (Industrial Countries), May 1997, U.S. Department of Health and Human Services.

http://aspe.hhs.gov/daltcp/reports/actaging. pdf
8. GARLICK, S.; SOAR, J. (2007). Human Capital, Innovation and the Productive Ageing: Growth and Senior Aged Health in the Regional Community through Engaged Higher Education, Annual AUCEA Conference, 2-4 July 2007, Alice Springs, Australia.

9. CAMARINHA-MATOS, L. M.; AFSARMANESH, H. (2011). Collaborative Ecosystems in Ageing Support, Proceedings of PRO-VE'11, 1719 Oct 2011, S. Paulo, Brazil, Adaptation and Value Creating Collaborative Networks, IFIP AICT Series 362/2011, Springer, pp. 177-188.

10. VAN DEN BROEK, G.; CAVALLO, F.; WEHRMANN, C. (Eds.) (2010). AALIANCE Ambient Assisted Living Roadmap. IOS Press. Amsterdam.

11. CAPSIL project (2010). CAPSIL Roadmap Document,

http://capsil.org/capsilwiki/index.php/CAP SIL_Roadmap_Document.

12. CAMARINHA-MATOS, L. M.; AFSARMANESH, H. (2011). Active Aging with Collaborative Networks. IEEE Technology and Society Magazine, Vol. 30, $\mathrm{N}^{\mathrm{o}}$ 4, Winter 2011, pp 12-25.

13. SENIOR project (2009). Good Practices in E-Inclusion, Ethical Guidance and Designing A Dialogue Roadmap. http://www.ifa-

fiv.org/attachments/059 Report\%20on\%20 good $\% 20$ practices $\% 20$ ethical\%20guidance $\% 20--$

$\% 2015 \% 20$ Nov\%2009\%20\%282\%29.pdf

14. AFSARMANESH, H., CAMARINHAMATOS, L.M., MSANJILA, S.S. (2009). A Well-Conceived Vision for Ex-Tending Professional Life of Seniors. In Leveraging knowledge for innovation in Collaborative Networks, Springer, pp. 681-692.

15. CAMARINHA-MATOS, L. M.; AFSARMANESH, H. (2004). A Roadmapping Methodology for Strategic Research on VO, in Collaborative Networked Organizations - A research agenda for emerging business models, cap. 7.1, Springer. 
16. CAMARINHA-MATOS, AFSARMANESH, H. (2010)

L. M.; Collaborative Ecosystems in Ageing Support. In Collaborative Networks for a Sustainable World, IFIP AICT Series 336/2010, Springer, pp. 177-188.

17. CAMARINHA-MATOS,

L. M.; AFSARMANESH, $\mathrm{H}$. (2012). Collaborative Networks in Active Ageing - A Roadmap Contribution to Demographic Sustainability, Production Planning \& Control, Vol. 23, No 4, April 2012, pp. 279-298.

18. CUMMINGS, T.G. (2005). Organization Development and Change. Thomson South-Western.

19. LLOYD, J.; WAIT, S. (2006). Integrated Care - A Guide for Policymakers, Alliance for Health and the Future, http://www.ilcuk.org.uk/files/pdf_pdf_7.pdf

20. MACADAM, M. (2008). Frameworks of Integrated Care for the Elderly: A Systematic Review, http://www.cprn.org/documents/49813_EN.pdf
21. CAMARINHA-MATOS, L. M.; AFSARMANESH, H. (2005). Collaborative Networks: A New Scientific Discipline, Journal of Intelligent Manufacturing, vol. 16, $\mathrm{N}^{\mathrm{o}} 4-5$, pp 439$452,2005$.

22. CAMARINHA-MATOS, L. M.; AFSARMANESH, H.; OLLUS, M. (Eds.) (2008). Methods and Tools For Collaborative Networked Organizations, Springer: New York.

23. DEL CURA, A.; CAMARINHA-MATOS, L. M.; FERRADA, F.; DEL CURA, P. (2009). New Organizational Forms to Extend The Professional Life. In Leveraging Knowledge for Innovation in Collaborative Networks, IFIP AICT 307, pp 709-720, Springer: Heidelberg.

24. CAMARINHA-MATOS, L. M. (2011). Guidelines for roadmap implementation. Deliverable D6.3, BRAID project, http://www.braidproject.eu/sites/default/file s/D6.3.pdf. 